\title{
METABOLISM OF A LIPID NANOEMULSION RESEMBLING LOW-DENSITY LIPOPROTEIN IN PATIENTS WITH GRADE III OBESITY
}

\author{
Simone Alves Dantas, I Elisabeth Salvatori Ficker," Carmen G. C. Vinagre, II \\ Barbara Maria Ianni, ${ }^{I}$ Raul Cavalcante Maranhão, II Charles Mady ${ }^{I}$
}

doi: $10.1590 / \mathbf{S 1 8 0 7 - 5 9 3 2 2 0 1 0 0 0 0 1 0 0 0 0 5}$

Dantas, SA Ficker ES Vinagre CGC, Ianni, BM Maranhão RC, Mady C. Metabolism of a lipid nanoemulsion resembling low-density lipoprotein in patients with grade III obesity. Clinics;2010:65(1):23-7.

INTRODUCTION: Obesity increases triglyceride levels and decreases high-density lipoprotein concentrations in plasma. Artificial emulsions resembling lipidic plasma lipoprotein structures have been used to evaluate low-density lipoprotein metabolism. In grade III obesity, low density lipoprotein metabolism is poorly understood.

OBJECTIVE: To evaluate the kinetics with which a cholesterol-rich emulsion (called a low-density emulsion) binds to low-density lipoprotein receptors in a group of patients with grade III obesity by the fractional clearance rate.

METHODS: A low-density emulsion was labeled with $\left[{ }^{14} \mathrm{C}\right]$-cholesterol ester and $\left[{ }^{3} \mathrm{H}\right]$-triglycerides and injected intravenously into ten normolipidemic non-diabetic patients with grade III obesity [body mass index higher than $40 \mathrm{~kg} / \mathrm{m}^{2}$ ] and into ten non-obese healthy controls. Blood samples were collected over 24 hours to determine the plasma decay curve and to calculate the fractional clearance rate.

RESULTS: There was no difference regarding plasma levels of total cholesterol or low-density lipoprotein cholesterol between the two groups. The fractional clearance rate of triglycerides was $0.086 \pm 0.044$ in the obese group and $0.122 \pm 0.026$ in the controls $(\mathrm{p}=0.040)$, and the fractional clearance rate of cholesterol ester $\left(\mathrm{h}^{-1}\right)$ was $0.052 \pm 0.021$ in the obese subjects and $0.058 \pm 0.015$ $(\mathrm{p}=0.971)$ in the controls.

CONCLUSION: Grade III obese subjects exhibited normal low-density lipoprotein removal from plasma as tested by the nanoemulsion method, but triglyceride removal was slower.

KEYWORDS: LDL metabolism; grade III obesity; artificial emulsions with lipidic structure; radioisotopes; triglyceride.

\section{INTRODUCTION}

The alterations in plasma lipids related to obesity that contribute to the higher incidence of cardiovascular disease in obese subjects mainly involve hypertriglyceridemia ${ }^{1,2}$ and low serum high-density lipoprotein (HDL) cholesterol. Increases in low-density lipoprotein (LDL) cholesterol levels are less frequent ${ }^{3,4}$ and have been less well investigated.

\footnotetext{
I Unidade Clínica de Miocardiopatias - Instituto do Coração - Hospital das Clinicas,Faculdade de Medicina da Universidade de São Paulo,São Paulo/ SP,Brazil

II Laboratório de Metabolismo de Lípides, Hospital das Clinicas,Faculdade de Medicina da Universidade de São Paulo,São Paulo/SP,Brazil

Email: si.dantas@uol.com.br

Tel: 55 11-30695957

Received for publication on July 21, 2009

Accepted for publication on October 11, 2009
}

Lipidic emulsions of defined composition that are made without protein can mimic the intravascular behavior of plasma lipoproteins. Injected into the bloodstream, chylomicron-like or LDL-like emulsions acquire circulating apolipoproteins that modulate the emulsion's metabolism and thus serve as a probe of the metabolic status of lipoproteins.

Accumulation of LDL in the plasma leading to hypercholesterolemia is mostly due to reduced LDL plasma clearance by the LDL receptors rather than increased lipoprotein production. In a recent study that used LDL-like nanoemulsions to probe LDL metabolism, we observed that, in sedentary subjects, LDL removal from the plasma compartment was slower than in athletes, although there was no difference in LDL cholesterol between sedentary subjects 
and athletes. ${ }^{5}$ This suggests that the increased removal of LDL in athletes is compensated for by an increased input of lipoprotein into plasma, either by increased conversion of LDL from VLDL or by increased direct LDL synthesis by the liver. To verify whether there are defects in LDL intravascular catabolism in obese subjects, we tested the plasma clearance of an LDL-like nanoemulsion in subjects with morbid grade III obesity (body mass index (BMI) $>40$ $\left.\mathrm{kg} / \mathrm{m}^{2}\right)$ in comparison with control subjects $\left(25 \mathrm{~kg} / \mathrm{m}^{2}\right)$ of normal weight.

\section{METHODS}

Ten obese (three male and seven female) and ten nonobese (four male and six female) subjects participated in the study. All participants were volunteers selected from the outpatient clinics of the institution. None of them were addicted to alcohol or had diabetes mellitus, liver, renal, thyroid, inflammatory, or neoplastic disease, and none were pregnant.

The design and objectives of the study were explained to the participants, and written informed consent was obtained. The study was approved by the Scientific and Ethics Committee.

Blood samples for the determination of plasma lipids and apolipoproteins were collected after a 12-h fast. Commercial enzymatic methods were used for the determination of total cholesterol (Boehinger-Mannheim, Penzberg, Germany), triglycerides (Abbott Laboratories) and HDL cholesterol after chemical precipitation of apo-B-containing lipoproteins with magnesium phosphotungstate. LDL cholesterol was calculated by the formula of Friedewald. ${ }^{6}$ Plasma apo AI and apo B were assayed by radial immunodiffusion (Lipo-Partigen R-ApoA-I and Nor-Partigen R-ApoB plates, Behing, Marburg, Germany). The LDL-like nanoemulsion was prepared from a lipid mixture composed of $40 \mathrm{mg} /$ mmol egg phosphatidylcholine, $20 \mathrm{mg} / \mathrm{mmol}$ cholesteryl oleate, $1 \mathrm{mg} / \mathrm{mmol}$ triolein, and $0.5 \mathrm{mg} / \mathrm{mmol}$ cholesterol purchased from Sigma Chemical Co. (St Louis, MO), in addition to a mixture of $\left[{ }^{14} \mathrm{C}\right]$ cholesteryl oleate and $\left[{ }^{3} \mathrm{H}\right]$-triglycerides purchased from Amersham International (Amersham, UK). Emulsification of the lipids by prolonged ultrasonic irradiation in aqueous media and two-step ultracentrifugation of the crude emulsion with density adjustment by the addition of $\mathrm{KBr}$ in order to obtain the LDE microemulsion was carried out by the method of Ginsburg et al. ${ }^{7}$ as modified by Maranhão et al. ${ }^{8}$

The participants fasted for $12 \mathrm{~h}$ prior to the test at 9 $\mathrm{AM}$, but they were allowed two standard meals during the study at 12:30 PM and 6 PM. The LDL-like nanoemulsion containing $70 \mathrm{kBq}$ of $\left[{ }^{14} \mathrm{C}\right]$ cholesteryl oleate and $121 \mathrm{kBq}$ of $\left[{ }^{3} \mathrm{H}\right]$ triacylglycerol at a total of $5-6 \mathrm{mg} / \mathrm{mmol}$ in a $100-$ $\mu$ volume was intravenously injected in a bolus. Plasma samples were collected over $24 \mathrm{~h}$; the first sample was collected 5 minutes after the injection of the nanoemulsion, and, after that, at 1, 2, 4, 6, 8, 12, and $24 \mathrm{~h}$ after the injection.

The safety of the radioactive dose injected into the subjects was assured according to radioprotection regulations ${ }^{9}$ described elsewhere. ${ }^{10}$ The procedures for lipid extraction and the addition of scintillation solution to each blood sample for radioactive counting and determination of the plasma decay curves of the radiosotopic labels of the nanoemulsion were performed as described previously using the ANACOMP software. ${ }^{11}$

All recorded variables were tabulated as means $\pm \mathrm{SD}$ or SEM. The normality of the data was tested by the Kolmogorov Smirnov test. Differences in the plasma lipids were evaluated using the Mann Whitney test, and differences with $\mathrm{p}<0.05$ were considered statistically significant for all comparisons. All statistical calculations were performed with the software SPSS ${ }^{\circledR}$ for Windows, version 10.0.

The safety of the radioactive dose intravenously injected into the patients was assured according to the regulations of the International Commission on Radiological Protection. ${ }^{9}$ The equivalent dose derived from the injected dose for each experiment was $0.1233 \mathrm{mSv}$, well below the 20-mSV annual limit for the intake of radionuclides.

\section{RESULTS}

Table 1 shows the individual physical characteristics and the plasma lipid and apolipoprotein profiles of the obese subjects and the controls. Obese subjects had LDL cholesterol levels similar to those of the controls, but the HDL cholesterol values were lower. On the other hand, fasting triglyceride levels were greater in the obese subjects $(\mathrm{p}=0.019)$ than in the controls. The apo B and apo A1 values were equal.

Figure 1 shows the decay curves of the cholesteryl ester label of the nanoemulsion. It is apparent that the curves obtained from the obese subjects did not differ from those of the non-obese controls. In fact, the calculated cholesteryl ester FCR of the morbid obese subjects was equal to that of the controls. The triglyceride FCR was lower in the morbid obese subjects than in the non-obese controls. In the non-obese controls, the triglyceride FCR was greater than that of the cholesteryl esters. In the obese, there was a trend (although not statistically significant) of a greater triglyceride FCR in comparison to the cholesteryl ester FCR. (Table 2) 
Table 1 - Individual physical characteristics and plasma lipid and apolipoprotein profiles (means \pm SD) for obese and control subjects

\begin{tabular}{lccc}
\hline & $\begin{array}{c}\text { Study group } \\
\text { Grade III obese subjects } \\
(\text { mean } \pm \text { SD) }\end{array}$ & $\begin{array}{c}c \\
\text { Controls } \\
\text { (mean } \pm \text { SD) }\end{array}$ \\
\hline Age (years) & $44 \pm 10$ & $46 \pm 12$ & 0.684 \\
BMI (kg/m $\left.{ }^{2}\right)$ & $48 \pm 5$ & $22 \pm 3$ & $<0.001$ \\
Cholesterol & $199 \pm 32$ & $186 \pm 23$ & 0.481 \\
(mg /dL) & $45 \pm 10$ & $58 \pm 17$ & 0.043 \\
LDL-C & $21 \pm 10$ & $29 \pm 7$ & 0.043 \\
HDL-C & $144 \pm 32$ & $101 \pm 45$ & 0.019 \\
$\begin{array}{l}\text { Triglycerides } \\
\text { (mg /dL) }\end{array}$ & $1.34 \pm 0.20$ & $1.39 \pm 0,27$ & 0.898 \\
Apo A-I (g/L) & $0.80 \pm 0.22$ & $0.90 \pm 0.21$ & 0.606 \\
Apo B (g/L) & & & \\
\hline
\end{tabular}

$\mathrm{BMI}=$ body mass index HDL-C $=$ high-density lipoprotein cholesterol; LDL-C = low-density lipoprotein cholesterol; Apo = apolipoprotein

Table 2 - Fractional clearance rate of the emulsion in obese and control subjects

\begin{tabular}{|c|c|c|c|}
\hline \multirow[b]{3}{*}{ FCR-TG $\left(h^{-1}\right)$} & \multirow{3}{*}{$\begin{array}{c}\text { Group }(\mathrm{n}) \\
\begin{array}{c}\text { Grade III obese subjects } \\
(\text { mean } \pm \text { SD })\end{array} \\
0.086 \pm 0.044\end{array}$} & \multirow{2}{*}{\multicolumn{2}{|c|}{$\begin{array}{c}\mathrm{p} \\
\text { Controls } \\
(\text { mean } \pm \mathrm{SD})\end{array}$}} \\
\hline & & & \\
\hline & & $0.122 \pm 0.026$ & 0.040 \\
\hline FCR-CE $\left(h^{-1}\right)$ & $0.052 \pm 0.021$ & $0.058 \pm 0.015$ & 0.971 \\
\hline
\end{tabular}

FCR -TG $\left(\mathrm{h}^{-1}\right)$ : fractional clearance rate of triglycerides

FCR -CE $\left(h^{-1}\right)$ : fractional clearance rate of cholesterol esters

\section{DISCUSSION}

In this study, in a group of morbid obese subjects, the removal of cholesteryl esters of an LDL-like nanoemulsion from plasma was similar to that observed in control subjects, but triglyceride removal was slower.

Injected into the blood stream, the LDL-like nanoemulsion acquires several circulating apolipoproteins such as apo CII and apo E. Apo CII is the co-factor for lipoprotein lipase and can eventually stimulate the enzyme to break down the residual triglycerides present in this nanoemulsion. On the other hand, apo $\mathrm{E}$ is recognized by the receptors that remove LDL from circulation. ${ }^{12}$

In several studies from our group, a triglyceriderich emulsion labeled with radioactive triglycerides and cholesteryl esters has been used to test the chylomicron metabolic pathway in several disorders that affect plasma lipid metabolism. ${ }^{13-19}$ This pathway is also common to very-low-density lipoproteins (VLDL) that (similarly to chylomicrons) undergo degradation of their triglyceride

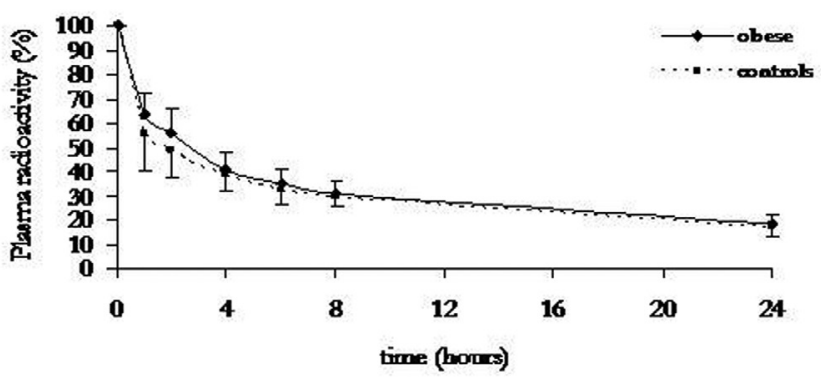

Figure 1 - Decay curves of the $\left[{ }^{3} \mathrm{H}\right]$-triglyceride emulsion obtained from obese and control subjects. The labeled emulsion was intravenously injected in a bolus, and blood samples were drawn at pre-established intervals over $24 \mathrm{~h}$ for measurement of radioactivity in a scintillation solution.

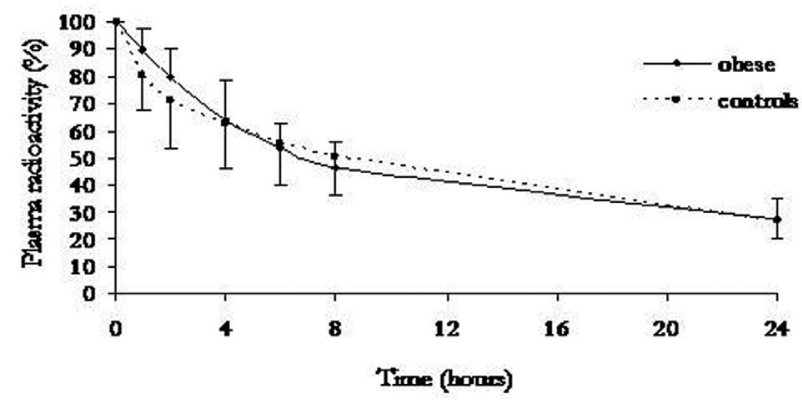

Figure 2 - Decay curves of the $\left[{ }^{14} \mathrm{C}\right]$-cholesteryl oleate emulsion obtained from obese and control subjects. The labeled emulsion was intravenously injected in a bolus, and blood samples were drawn at pre-established intervals over $24 \mathrm{~h}$ for measurement of radioactivity in a scintillation solution.

content by lipoprotein lipase using apo CII as a co-factor.

In obese subjects, the removal of the triglycerides of the chylomicron-like emulsion from plasma was similar to that in the non-obese controls, but the cholesteryl ester removal was slower. ${ }^{20}$ This finding suggests that, although the lipolysis process occurs normally in the obese, there is difficulty in removing the remnants from circulation, a defect that is associated with atherosclerosis development. In the correlation study on obese subjects that was subsequently performed, a negative correlation between cholesteryl ester removal (i.e., remnant removal) and BMI was found; in contrast, lipolysis correlated positively with BMI. ${ }^{21}$ One can hypothesize that the excess insulin in the plasma of obese subjects stimulates lipolysis, whereas their obesity inhibits the mechanisms of remnant removal, in which LDL receptors are also involved. However, when the morbidly obese were compared with obese subjects, the former showed diminished lipolysis, indicating that additional defects appear in individuals with extremely high BMIs. Another aspect is alterations in glucagonlike peptide 1 , which modifies the postprandial rise in triglyceride concentration, whose effects are not completely understood in morbid obesity, despite the functions already described. ${ }^{22,23}$ Yet another aspect which may be mentioned is 
the fact that treatment of obese patients with the cholesterol removing agent sibutramine does not appear to correct the hypertension normally associated to obesity. ${ }^{24}$

Whereas the chylomicron-like emulsion probes the lipolysis and remnant removal of triglyceride-rich lipoproteins, the LDL-like nanoemulsion probes the function of the mechanisms that remove LDL from circulation. The fact that the removal of the LDL-like nanoemulsion was normal in the morbidly obese indicates that those mechanisms are not altered in these subjects. This was confirmed by the fact that LDL cholesterol and apolipoprotein B concentrations were both normal, although different removal rates associated with different synthesis rates might have resulted in equal LDL concentrations, a possibility that we explored in this study regarding the removal rates.

The fact that, in both control and obese subjects, the triglycerides of the LDL-like emulsion were removed faster than the cholesteryl ester indicates that lipolysis also occurs in those particles as it does in chylomicronlike emulsions. The finding that the triglycerides of the LDL-like nanoemulsion were removed more slowly in the morbidly obese than in the controls is noteworthy. There are significant structural differences between LDL-like particles and chylomicron-like emulsion particles. While in the chylomicron-like emulsion, the triglyceride component is prevalent, constituting up to $70 \%$ of the particle composition, in LDL-like particles, the triglyceride content is rather residual. On the other hand, the particle diameter of the chylomicron-like emulsion is two to four times greater than that of the LDL-like preparation. Nonetheless, both preparations showed slower triglyceride removal in the morbidly obese subjects (but not in the obese subjects), as compared with the controls.

\section{REFERENCES}

1. Krotkiewski M, Bjorntorp P, Sjostrom L, Smith U. Impact of obesity on metabolism in men and women. Importance of regional adipose tissue distribution. J Clin Invest. 1983;72:1150-62.

2. Lamon-Fava S, Wilson PW, Schaefer EJ. Impact of body mass index on coronary heart disease risk factors in men and women. The Framingham Offspring Study. Arterioscler Thromb Vasc Biol. 1996;16:509-15.

3. Denke MA, Sempos CT, Grundy SM. Excess body weight. An underrecognized contributor to dyslipidemia in White American women. Arch Intern Med. 1994;154:401-10.

4. Seidell JC, Cigolini M, Charzewska J, Ellsinger BM, Di Biase G. Fat distribution in European women: a comparison of anthropometric measurements in relation to cardiovascular risk factors. Int J Epidemiol. 1990;19:303-8.

5. Vinagre CG, Ficker ES, Finazzo C, Alves MJ, de Angelis K, Irigoyen $\mathrm{MC}$, et al. Enhanced removal from the plasma of LDL-like nanoemulsion cholesteryl ester in trained men compared with sedentary healthy men. J Appl Physiol. 2007;103:1166-71.

6. Friedewald WT, Levy RI, Fredrickson DD. Estimation of the concentration of low-density lipoprotein cholesterol in plasma, without use of the preparative ultracentrifuge. Clin Chem. 1972;18:499-502.

7. Ginsburg GS, Small DM, Atkinson D. Microemulsion of phospholipids and cholesterol esters Protein-free models of low density lipoprotein. J Biol Chem.1982;257:8216-27.

8. Maranhão RC, César TB, Pedroso-Mariani SR, Hirata MH, Mesquita $\mathrm{CH}$. Metabolic behavior in rats of a nonprotein microemulsion resembling low density lipoprotein. Lipids. 1993;28:691-6.

9. Sowby FS. Radiation protection. ICRP publication 30. part I. Limits for intakes of radionuclides by workers. In: Sowby FS. Oxford: Pergamon; 1984.
10. Maranhao RC, Graziani SR, Yamaguchi N, Melo RF, Latrilha MC, Rodrigues DG, et al. Association of carmustine with a lipid emulsion: in vitro, in vivo and preliminary studies in cancer patients. Cancer Chemother Pharmacol. 2002;49:487-98.

11. Mesquita CH. Cinética do quilomícron marcado com $3 \mathrm{H}-\mathrm{TG}$ e $14 \mathrm{C}$ CE. Análise compartimental auxiliar. São Paulo: Instituto de Pesquisas Energéticas e Nucleares (IPEN), 1994.

12. Swarnakar S, Reyland ME, Deng J, Azhar S, Williams DL. Selective uptake of low density lipoprotein-cholesterol ester is enhanced by inducible apolipoprotein E expression in cultured mouse adrenocortical cells. J Biol Chem. 1998;273:12140-7.

13. Maranhão RC, Feres MC, Martins $\mathrm{MT}$, Mesquita $\mathrm{CH}$, Toffoletto $\mathrm{O}$, Vinagre CGC, et al. Plasma kinetics of a chylomicron-like emulsion in patients with coronary artery disease. Atherosclerosis. 1996;126:15-25.

14. Borba EF, Bonfa E, Vinagre CG, Ramires JA, Maranhao RC. Chylomicron metabolism is markedly altered in systemic lupus erythematosus. Arthritis Rheum. 2000;43:1033-40.

15. Vinagre CGC, Stolf NA, Bocchi E, Maranhao RC. Chylomicron metabolism in patients submitted to cardiac transplantation. Transplantation. 2000;69:532-7.

16. Santos RD, Sposito AC, Ventura LI, César LA, Ramires JA, Maranhao RC. Effect of pravastatin on plasma removal of a chylomicronlike emulsion in men with coronary artery disease. Am J Cardiol. 2000;85:1163-6.

17. Santos RD, Ventura LI, Sposito AC, Schreiber R, Ramires JA, Maranhao $\mathrm{RC}$. The effects of gemfibrozilupon the metabolism of chylomicron-like emulsions in patientswith endogenous hypertriglyceridemia. Cardiovasc Res. 2001;49:456-65. 
18. César TB, Oliveira MR, Mesquita CH, Maranhão RC. High cholesterol intake modifies chylomicron metabolism in normolipidemic young men. J Nutr. 2006;136:971-6.

19. Hosni JJ, Vinagre CG, Mady C, Maranhão RC. Lipolysis of emulsion models of triglyceride-rich lipoproteins is altered in male patients with abdominal aorta aneurysm. Braz J Med Biol Res. 2007;40:305-7.

20. Oliveira MR, Maranhão RC. Plasma kinetics of a chylomicron-like emulsion in normolipidemic obese women after a short-period weight loss by energy-restricted diet. Metabolism. 2002;51:1097-103.

21. Oliveira MR, Maranhão RC. Relationships in women between body mass index and the intravascular metabolism of chylomicron-like emulsions. Int J Obes Relat Metab Disord. 2004;28:1471-8.
22. Meier JJ, Gethmann A, Götze O, Gallwitz B, Holst JJ, Schmidt WE, et al. Glucagon-like peptide 1 abolishes the postprandial rise in triglyceride concentrations and lowers levels of non-esterified fatty acids in humans. Diabetologia 2006;49:452-8.

23. Adeli K, Lewis GF. Intestinal lipoprotein overproduction in insulinresistant states. Curr Opin Lipidol. 2008;19:221-8.

24. de Lemos HP Jr, Atallah AN, de Lemos AL. Can sibutramine alter systemic blood pressure in obese patients? Systematic review and metaanalysis. Sao Paulo Med J. 2008;126:342-6. 
